\title{
Influence of Chromium Concentration on the Electron Magnetic Resonance Linewidth of $\mathrm{Cr}^{3+}$ in $\mathrm{SrTiO}_{3}$
}

\author{
Ronaldo Sergio de Biasi*, Maria Lúcia Netto Grillo \\ ${ }^{a}$ Seção de Engenharia Mecânica e de Materiais, Instituto Militar de Engenharia - IME, \\ CEP 22290-270, Rio de Janeiro, RJ, Brazil \\ ${ }^{\mathrm{b}}$ Instituto de Física, Universidade do Estado do Rio de Janeiro - UERJ, \\ CEP 20550-013, Rio de Janeiro, RJ, Brazil
}

Received: July 6, 2011; Revised: May 8, 2012

\begin{abstract}
Electron magnetic resonance (EMR) spectra of $\mathrm{Cr}^{3+}$ ions in samples of chromium-doped strontium titanate $\left(\mathrm{SrTiO}_{3}\right)$ have been studied at room temperature for chromium concentrations between 0.20 and $1.00 \mathrm{~mol} \%$. According to previous studies, chromium substitutes $\mathrm{Ti}^{4+}$ sites in the lattice and its preferred valence state is $\mathrm{Cr}^{4+}$, which is EMR silent in the $\mathrm{X}$-band, but the trivalent state can be produced by illumination or codoping with $\mathrm{Nb}$. In the present work, the codoping method was used; the results show the electron magnetic resonance linewidth of the $\mathrm{Cr}^{3+}$ spectrum increases with increasing chromium concentration and that the range of the exchange interaction between $\mathrm{Cr}^{3+}$ ions is about $0.96 \mathrm{~nm}$.
\end{abstract}

Keywords: ceramics, electron magnetic resonance, strontium titanate, chromium, niobium

\section{Introduction}

Strontium titanate $\left(\mathrm{SrTiO}_{3}\right)$ is a high dielectric constant ceramic material with several industrial applications $\mathrm{s}^{1-4}$, such as memory devices, oxygen sensors, electro-optical devices and flexible dielectric waveguides, whose electrical properties can be changed by the presence of transition metal and rare earth impurities such as iron and gadolinium ${ }^{5,6}$. EMR spectroscopy is a convenient method for studying these impurities within the $\mathrm{SrTiO}_{3}$ structure. In this work, we study the effect of chromium concentration on the EMR spectrum of $\mathrm{Cr}^{3+}$ in polycrystalline $\mathrm{SrTiO}_{3}$ codoped with chromium and niobium. The importance of this investigation is twofold. First, once the effects of chromium concentration on the spectrum are known, it becomes possible to use EMR results to study the effects of other impurities ${ }^{7-9}$ on the valence state of the chromium ion in $\mathrm{SrTiO}_{3}$. Second, knowledge of the range of the exchange interaction between $\mathrm{Cr}^{3+}$ ions contributes to a better understanding of the electrical and magnetic properties ${ }^{10,11}$ of doped strontium titanate.

\section{Background}

\subsection{Crystal structure of strontium titanate}

Strontium titanate $\left(\mathrm{SrTiO}_{3}\right)$ crystallizes in the perovskite structure $^{12}$ conforming to the space group $\operatorname{Pm} \overline{3} m\left(O_{h}^{1}\right)$. There are two distinct cation sites, one with twelve nearest-neighbor oxygen ions, occupied by $\mathrm{Sr}$ atoms, and one with six nearest-neighbor oxygen atoms, occupied by Ti atoms.

*e-mail: rsbiasi@ime.eb.br

\subsection{EMR of chromium-doped strontium titanate}

Analysis of the EMR spectrum of single-crystal chromium-doped strontium titanate ${ }^{13}$ shows that $\mathrm{Cr}^{4+}$ ions substitutionally replace titanium ions in the lattice. $\mathrm{Cr}^{4+}$ ions cannot be observed at $\mathrm{X}$ band due to a high crystal field splitting, but the trivalent state can be produced under illumination ${ }^{13}$ or by codoping with $\mathrm{Nb}^{[14]}$. The spectrum of $\mathrm{Cr}^{3+}$ under illumination consists of a central line $(\mathrm{g} \approx 1.978)$ due to ${ }^{50} \mathrm{Cr},{ }^{52} \mathrm{Cr}$ and ${ }^{54} \mathrm{Cr}$ and a hyperfine quartet due to the ${ }^{53} \mathrm{Cr}$ isotope ${ }^{13}$.

\subsection{EMR of dilute solid solutions}

The theory of dipolar broadening in diluted solid solutions was developed in Kittel and Abrahams ${ }^{15}$ and extended in de Biasi and Fernandes ${ }^{16}$ to take exchange interactions into account. The main results of the theory can be summarized as follows:

The lineshape is a truncated Lorentzian;

The peak-to-peak first derivative linewidth may be expressed as

$\Delta H_{p p}=\Delta H_{0}+\Delta H_{d}=\Delta H_{0}+C_{1} f_{e}$

where $\Delta H_{0}$ is the intrinsic linewidth, $\Delta H_{d}$ is the dipolar broadening, $C_{1}$ is a constant and $f_{e}$ is the concentration of substitutional ions of the paramagnetic impurity not coupled by the exchange interaction, which can be expressed as

$f_{\mathrm{e}}=f(1-f)^{z\left(r_{c}\right)}$

where $f$ is the impurity concentration, $z\left(r_{c}\right)$ the number of cation sites included in a sphere of radius $r_{c}$ and $r_{c}$ the effective range of the exchange interaction. 
The intensity of the absorption line is

$$
I=C_{2} f_{e}
$$

where $C_{2}$ is a constant.

The analysis above is based on the assumption of two ion populations, one with no exchange, which is responsible for the normal paramagnetic line, and another which, due to exchange, is either EPR silent (if the coupling is antiferromagnetic) or gives rise to a much broader line (if the coupling is ferromagnetic).

\section{Experimental Procedure and Results}

\subsection{Sample preparation}

The chromium/niobium doped samples used in this study were prepared from high-purity $\mathrm{SrTiO}_{3}$ (Aldrich, 99\%), $\mathrm{Cr}_{2} \mathrm{O}_{3}$ (Aldrich, 99.9\%) and $\mathrm{Nb}_{2} \mathrm{O}_{5}$ (Aldrich, 99.99\%) powders by grinding them together and then firing the mixture for 24 hours at $1200{ }^{\circ} \mathrm{C}$ in air. Since niobium was intended to act as an electron donor, we used equal molar concentrations of $\mathrm{Cr}$ and $\mathrm{Nb}$ in each sample. The chromium concentrations and reagent masses are shown in Table 1. Room-temperature X-ray diffraction patterns (Figure 1) of the samples matched, within experimental error, the spectrum ${ }^{17}$ of $\mathrm{SrTiO}_{3}$. No other phases were detected.

\subsection{Magnetic resonance measurements}

All magnetic resonance measurements were performed at room temperature and $9.50 \mathrm{GHz}$ using a Varian

Table 1. Chromium and niobium concentrations and reagent masses for the samples used in this work.

\begin{tabular}{cccc}
\hline$f_{\mathrm{Cr}, \mathbf{N b}}(\mathbf{m o l} \%)$ & $m_{\mathrm{Cr}_{2} \mathrm{O}_{3}}(\mathbf{g})$ & $m_{\mathrm{Nb}_{2} \mathbf{O}_{5}}(\mathbf{g})$ & $m_{\mathrm{SrTiO}_{3}}(\mathbf{g})$ \\
\hline 0.20 & 0.0017 & 0.0030 & 1.9953 \\
0.40 & 0.0033 & 0.0058 & 1.9909 \\
0.60 & 0.0050 & 0.0087 & 1.9863 \\
0.80 & 0.0067 & 0.0117 & 1.9816 \\
1.00 & 0.0083 & 0.0145 & 1.9772 \\
\hline
\end{tabular}

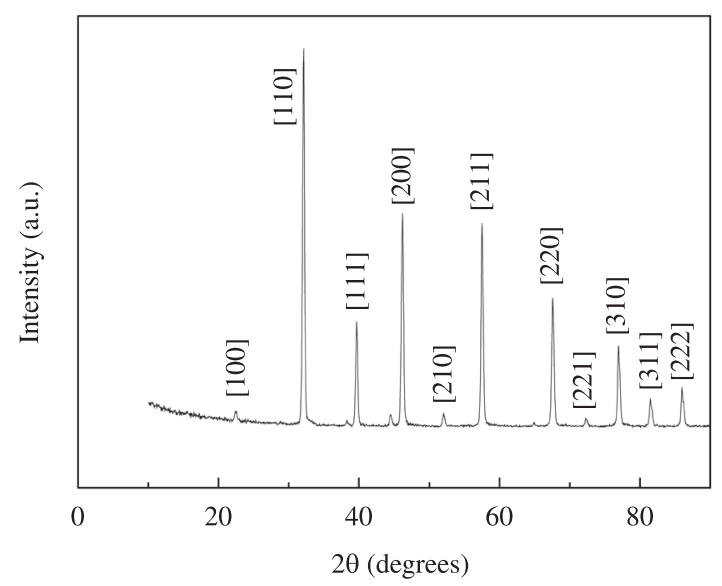

Figure 1. X-ray diffraction pattern of a $\mathrm{SrTiO}_{3}$ sample doped with $1.0 \mathrm{~mol} \% \mathrm{Cr}$ and $1.0 \mathrm{~mol} \% \mathrm{Nb}$. The indices were taken from JCPDS no. 86-0179.
E-12 spectrometer with $100 \mathrm{kHz}$ field modulation. The microwave power was $200 \mathrm{~mW}$ and the modulation amplitude was $0.1 \mathrm{mT}$. The magnetic field was calibrated with an NMR gaussmeter.

Spectra of samples of $\mathrm{SrTiO}_{3}$ doped with 0.2 and $1.0 \mathrm{~mol} \% \mathrm{Cr}$ and $\mathrm{Nb}$ are shown in Figures 2 and 3. Only the line due to the $\mathrm{Cr}^{3+}-1 / 2 \rightarrow 1 / 2$ transition is clearly seen; the $g$-value of this line is $1.978 \pm 0.001$, in good agreement with the value reported in Müller ${ }^{13}$. The lines due to the other transitions, like the $\mathrm{Gd}^{3+}$ lines in the same compound ${ }^{18}$, are broader because of lattice strain and are responsible, together with $\mathrm{Cr}^{3+}-\mathrm{Cr}^{3+}$ pairs within the range of the exchange interaction, for the feature near $0.34 \mathrm{~T}$ in Figures 2 and 3. Linewidth and intensity data for the $\mathrm{Cr}^{3+}-1 / 2 \rightarrow 1 / 2$ transition are shown in Table 2 for several chromium concentrations.

\section{Discussion}

The theoretical concentration dependence of the peak-to-peak linewidth $\Delta H_{\mathrm{pp}}$, given by Equation 1, is shown in Figure 4 for $\Delta H_{0}=0.6 \mathrm{mT}$ and eight different ranges of



Figure 2. EMR spectrum of a $\mathrm{SrTiO}_{3}$ sample doped with $0.2 \mathrm{~mol} \%$ $\mathrm{Cr}$ and $0.2 \mathrm{~mol} \% \mathrm{Nb}$.



Figure 3. EMR spectrum of a $\mathrm{SrTiO}_{3}$ sample doped with $1.0 \mathrm{~mol} \%$ $\mathrm{Cr}$ and $1.0 \mathrm{~mol} \% \mathrm{Nd}$. 


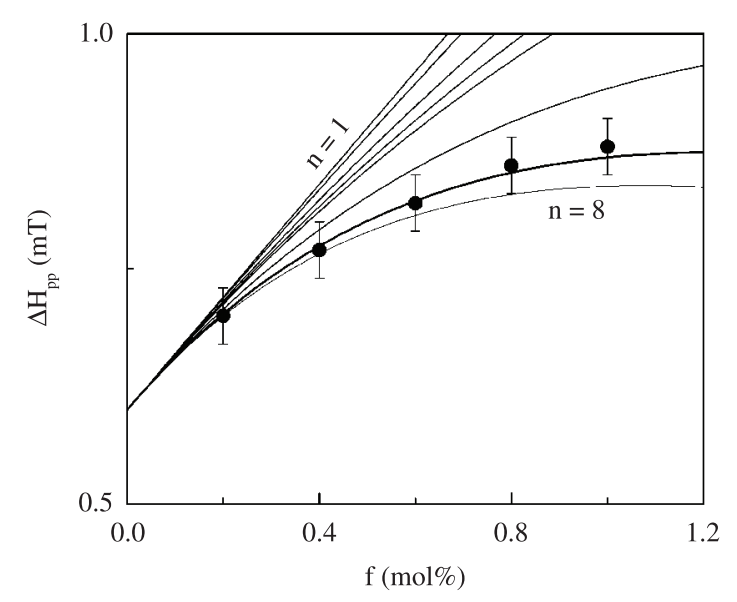

Figure 4. Concentration dependence of the peak-to-peak linewidth, $\Delta H_{\mathrm{pp}}$, in $\mathrm{Cr} / \mathrm{Nb}$-doped $\mathrm{SrTiO}_{3}$. The circles are experimental points; the curves represent results of calculations for eight different ranges of the exchange interaction.

Table 2. Experimental results for the $\mathrm{Cr}^{3+}-\mathrm{SrTiO}_{3}$ system $(\mathrm{T}=300 \mathrm{~K}, \mathrm{v}=9.50 \mathrm{GHz})$.

\begin{tabular}{ccc}
\hline$f_{\text {Cr }}(\mathbf{m o l} \%)$ & $\Delta H_{\mathrm{pp}}(\mathbf{m} \mathbf{T})$ & $I$ (A.U.) \\
\hline 0.20 & 0.70 & 0.55 \\
0.40 & 0.77 & 0.90 \\
0.60 & 0.82 & 1.20 \\
0.80 & 0.86 & 1.30 \\
1.00 & 0.88 & 1.50 \\
\hline
\end{tabular}

Table 3. Values of $r_{c}$ and $z\left(r_{c}\right)$ for $\mathrm{SrTiO}_{3}$

\begin{tabular}{ccc}
\hline$n$ & $r_{c}(\mathbf{n m})$ & $z\left(r_{c}\right)$ \\
\hline 1 & 0.00 & 0 \\
2 & 0.39 & 6 \\
3 & 0.55 & 18 \\
4 & 0.68 & 26 \\
5 & 0.78 & 32 \\
6 & 0.87 & 56 \\
7 & 0.96 & 80 \\
8 & 1.11 & 92 \\
\hline
\end{tabular}

the exchange interaction. The values of $r_{c}$ and $\mathrm{z}\left(r_{c}\right)$ for the first eight coordinate spheres are listed in Table 3 , where $n$ is the number of the order of each coordinate sphere $(n=1$ includes no neighboring sites, and so on). The values of $z\left(r_{c}\right)$ are those appropriate to the lattice of $\mathrm{SrTiO}_{3}$; the values of $r_{c}$ were calculated from the lattice constant at room temperature as measured by X-ray diffraction ${ }^{17}$, $a_{\mathrm{o}}=0.3901 \mathrm{~nm}$. The experimental data are also shown in

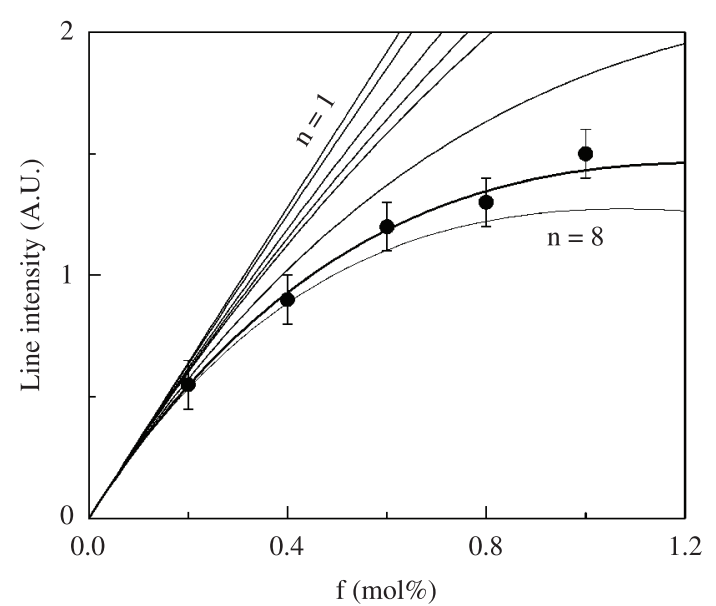

Figure 5. Concentration dependence of the line intensity in $\mathrm{Cr} /$ $\mathrm{Nb}$-doped $\mathrm{SrTiO}_{3}$. The circles are experimental points; the curves represent the results of calculations for eight different ranges of the exchange interaction.

Figure 4. The experimental results fit the theoretical curve for $n=7$, which corresponds, according to Table 3 , to a range $r_{c}=0.96 \pm 0.10 \mathrm{~nm}$ for the exchange interaction. Figure 5 shows the theoretical (Equation 3) and experimental (Table 2) intensity data, estimated using the expression $I=A\left(\Delta H_{\mathrm{pp}}\right)^{2}$, where $I$ is the line intensity, $A$ is the line amplitude and $\Delta H_{\mathrm{pp}}$ is the peak-to-peak linewidth. The vertical scale is arbitrary and was chosen so as to provide the best fit of the experimental points to the theoretical curve for $n=7$, or $z\left(r_{c}\right)=80$. The agreement was found to be very good.

\section{Conclusions}

Since the linewidth and intensity of the EMR spectrum of $\mathrm{Cr}^{3+}$ in $\mathrm{SrTiO}_{3}$ increase with $\mathrm{Cr}$ concentration and the experimental results are fitted well by a theoretical model, niobium codoping seems to be a reliable way to change the valence state of the chromium ions from $\mathrm{Cr}^{4+}$ to $\mathrm{Cr}^{3+}$ in substitutional titanium sites of chromium-doped strontium titanate. The fact that the range of the exchange interaction of $\mathrm{Cr}^{3+}$ in $\mathrm{SrTiO}_{3}$ is much larger than in $\mathrm{Y}_{2} \mathrm{O}_{3}{ }^{[19]}(0.96$ and $0.64 \mathrm{~nm}$, respectively) is probably due to a more favorable bonding angle in $\mathrm{SrTiO}_{3}$, that favors indirect exchange ${ }^{20}$.

\section{Acknowledgements}

The authors thank CNPq and CAPES for financial support.

\section{References}

1. Suchanek WL and Yoshimura M. Preparation of strontium titanate thin films by the hydrothermal-electrochemical method in a solution flow system. Journal of the American Ceramic Society. 1998; 81(11):2864-2868. http://dx.doi. org/10.1111/j.1151-2916.1998.tb02707.x

2. Haertling GH. Ferroelectric ceramics: history and technology. Journal of the American Ceramic Society. 1999; 82(4):797818. http://dx.doi.org/10.1111/j.1151-2916.1999.tb01840.x

3. Srdic VV and Djenadic RR. Nanocrystalline titanate powders: synthesis and mechanisms of perovskite particles 
formation. Journal of Optoelectronics and Advanced Materials. 2005; 7(6):3005-3013.

4. Xiang F, Wang H, Yang H, Shen ZY and Yao X. Low loss flexible $\mathrm{SrTiO}_{3} / \mathrm{POE}$ dielectric composites for microwave application. Journal of Electroceramics. 2010; 24(1):20-24. http://dx.doi.org/10.1007/s10832-008-9453-y

5. Kazan S, Sale AG, Gatiiatova JI, Valeev VF, Khaibullin RI and Mikailzade FA. Magnetic resonance and ferromagnetic behaviour in Fe-implanted $\mathrm{SrTiO}_{3}$. Solid State Communications. 2010; 150(3-4):219-222. http://dx.doi. org/10.1016/j.ssc.2009.10.041

6. Singh P, Singh P, Singh S, Parkash O and Kumar D. Electrical conduction behavior and immittance analysis of Gd and Mn substituted strontium titanate. Journal Of Materials Science. 2008; 43(3):989-1101. http://dx.doi.org/10.1007/ s10853-007-2245-y

7. Olaya D, Pan F, Rogers CT and Price JC. Superconductivity in La-doped strontium titanate thin films. Applied Physics Letters. 2004; 84(20):4020-4022. http://dx.doi. org/10.1063/1.1751213

8. Cumming DJ, Kilner JA and Skinner S. Structural properties of Ce-doped strontium titanate for fuel cell applications. Journal of Materials Chemistry. 2011;21(13):5021-5026. http://dx.doi. org/10.1039/c0jm03680c

9. TkachA, Vilarinho PM and Kholkin AL. Dependence of dielectric properties of manganese-doped strontium titanate ceramics on sintering atmosphere. Acta Materialia. 2006; 54(20):53855391. http://dx.doi.org/10.1016/j.actamat.2006.07.007

10. Tkach A, Okhay O, Vilarinho PM and Kholkin AL. High dielectric constant and tunability of strontium titanate ceramics modified by chromium doping. Journal of Physics: Condensed Matter. 2008; 20(41). http://dx.doi.org/10.1088/0953$8984 / 20 / 41 / 415224$

11. Chang C-H and Shen Y-H. Synthesis and characterization of chromium doped $\mathrm{SrTiO}_{3}$ photocatalyst. Materials
Letters. 2006; 60(1):129-132. http://dx.doi.org/10.1016/j. matlet.2005.08.005

12. Abramov YA, Tsirelson VG, Zavodnik VE, Ivanov SA and Brown ID. The chemical bond and atomic displacements in $\mathrm{SrTiO}_{3}$ from X-ray diffraction analysis. Acta Crystallographica Section B, 1995; 51(6):942-951. http://dx.doi.org/10.1107/ S0108768195003752

13. Müller KA. Resonance paramagnetique du $\mathrm{Cr}^{3+}$ dans des monocristaux de $\mathrm{SrTiO}_{3}$. Archives des Sciences (Geneva). 1958; (1):150-152.

14. Mattina F, Bednorz JG, Alvarado SF, Shengelaya A, Müller $\mathrm{KA}$ and Keller $\mathrm{H}$. Controlled oxygen vacancies and space correlation with $\mathrm{Cr}^{3+}$ in $\mathrm{SrTiO}_{3}$. Physical Review B. 2009; 80(7). http://dx.doi.org/10.1103/PhysRevB.80.075122

15. Kittel $\mathrm{C}$ and Abrahams E. Dipolar broadening of magnetic resonance lines in magnetically diluted crystals. Physical Review. 1953; 90(2):238-239. http://dx.doi.org/10.1103/ PhysRev.90.238

16. de Biasi RS and Fernandes AAR. The ESR linewidth of dilute solid solutions. Journal of Physics C: Solid State Physics. 1983; 16(28):5481-5489.http://dx.doi. org/10.1088/0022-3719/16/28/015

17. Joint Committee on Powder Diffraction Standards. JCPDS No. 86-0179.

18. Rimai L and De Mars GA. Electron paramagnetic resonance of trivalent gadolinium ions in strontium and barium titanates. Physical Review. 1962; 127(3):702-710. http://dx.doi. org/10.1103/PhysRev.127.702

19. de Biasi RS and Grillo ML. Electron spin resonance of chromia-yttria solid solutions. Journal of Physics and Chemistry of Solids. 2005; 66(10):1806-1809. http://dx.doi. org/10.1016/j.jpcs.2005.08.089

20. Anderson PW. New Approach to the Theory of Superexchange Interactions. Physical Review. 1959; 115(1):2-13. http://dx.doi. org/10.1103/PhysRev.115.2 